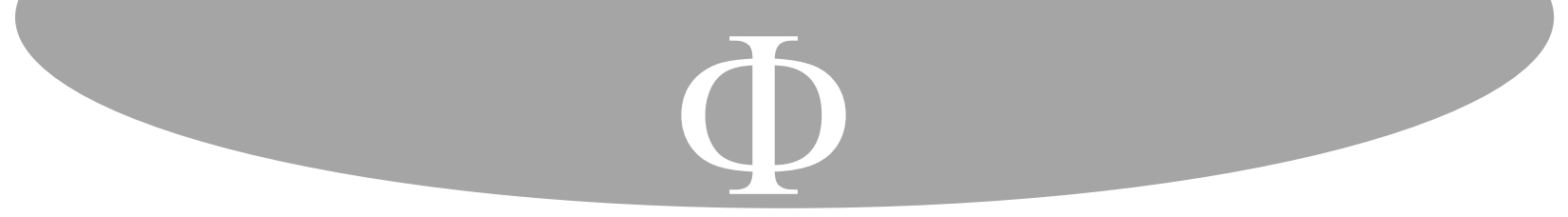

\title{
Unidade cordial da pessoa humana e da comunidade: o símbolo do coração nos escritos e na recepção artística de Agostinho de Hipona*
}

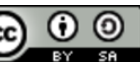

\begin{abstract}
Para citar este artículo: Dupont, Anthony y Ribeiro Lin, Davi C. «Unidade cordial da pessoa humana e da comunidade: o símbolo do coração nos escritos e na recepção artística de Agostinho de Hipona».
\end{abstract}

Franciscanum 175, Vol. 63 (2021): 1-22.

\section{Resumo}

Este artigo irá examinar a concepção de Agostinho de Hipona (354-430) sobre o coração humano, visto que, ocupando o lugar de um cardiologista, Agostinho prescreve um tratamento terapêutico intensivo. Serão considerados três movimentos essenciais do cor agostiniano. Primeiramente, Agostinho propõe uma busca pelo coração, a câmara secreta, o centro vital interior que necessita ser reencontrado. Uma vez localizado o coração, somos levados a um segundo movimento: o retorno ao coração. Depois de diagnosticar sua própria doença cardíaca, um coração vazio, Agostinho propõe uma terapia, a volta ao coração no encontro com um terapeuta divino, o Cristo; e um remédio potente, o esmagamento do coração. Terceiro, ascende-se com seu coração: o coração se eleva ao alto, sursum cor. Um coração saudável é um coração ascendente, com o amor como seu marca-passo. Retornar ao coração significa, portanto, voltar ao núcleo de uma autêntica existência, no chamado para

\footnotetext{
${ }^{*}$ Esta pesquisa foi estimulada pela visita do prof. Anthony Dupont ao Brasil, em abril de 2019, quando foi convidado a participar, dentre diversas atividades, do Simpósio «Grandes respostas em tempos difíceis: resiliencia e esperança» ocorrido na Faculdade de Filosofia e Ciência Humanas (FAFICH) da Universidade Federal de Minas Gerais (UFMG).

** Professor da Faculdade de Teologia e Ciência da Religião na Katholieke Universiteit Leuven (KU Leuven) na área de antiguidade clássica, história do cristianismo e teologia patrística. Ele é membro do Conselho do Instituto Histórico Agostiniano (Lovaina), da revista científica Augustiniana, do Comitê Científico da Corpus Christianorum Christianorum Série Latina / Continuatio Mediaevalis, e das duas séries de monografia Instrumenta Patristica et Mediaevalia e LECTIO: Studies in the Transmission de Textos e Idéias [Brepols] e Reading Augustine [Bloomsbury]. Contacto: anthony.dupont@kuleuven.be. ORCID: https://orcid.org/00000003-4967-7541

${ }^{* * *}$ Davi C. Ribeiro Lin é doutor em teologia pela Faculdade Jesuíta (FAJE) e pela Katholieke Universiteit Leuven (KU Leuven, Bélgica) com a tese «Relational Confession as Therapy of the Heart? A Postmodern Dialogue between Augustine of Hippo's Confessions and Elementary Experience in Psychology». Psicólogo pela Universidade Federal de Minas Gerais, especialista em psicologia clínica, mestre em teologia pelo Regent College (Vancouver, Canadá). Contacto: davichangbh@gmail.com.
} 


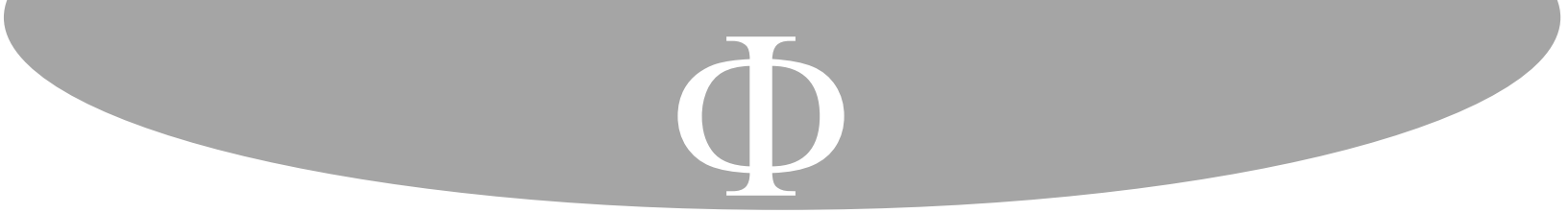

Este símbolo é baseado em duas fórmulas extraídas da obra Confissões: «tu nos havias transpassado o coração com as flechas do teu amor, e trazíamos tuas palavras dentro das nossas entranhas» ${ }^{2} \mathrm{e}$ «tocaste-me o coração com a tua palavra, e comecei a amar-te» ${ }^{3}$.

Essas duas citações aludem ao fato de que, em sua busca pela verdadeira felicidade, o jovem Agostinho, posteriormente à sua exploração do maniqueísmo, do ceticismo e do neoplatonismo finalmente se reencontrou com a Bíblia. Através das palavras das Escrituras, Deus havia tocado Agostinho tão profundamente que sua flecha perfurou seu coração e a consequência foi sua conversão a um amor responsivo. Em um nível literal, em sua biografia, ele descreve que as palavras da Bíblia foram o catalisador de sua conversão, ou mais precisamente: o desfibrilador. Assim como o desfibrilador é um equipamento para estimular os batimentos cardíacos em situações de parada cardíaca ou arritmia, o contato com as Escrituras lhe deu a vida em meio a uma crise do coração. Instigado por um comando não identificado, «pegue e leia, pegue e leia», Agostinho abriu a Bíblia e leu Rom. 13.13-14. Ao reconhecer este chamado do apóstolo Paulo para conversão, «infundiu uma luz de segurança em meu coração, todas as trevas da dúvida desapareceram» ${ }^{4}$. Em um jardim em Milão, em agosto do ano 386, Agostinho se converteu ao cristianismo. As duas citações sobre o coração trespassado também têm um nível mais profundo, mais amplo que o evento do jardim milanês de 386: se refere à conversão do coração, que abrange a totalidade da vida e da pessoa de Agostinho.

O coração é um elemento central, tanto na experiência de vida pessoal de Agostinho quanto em seu pensamento. O uso da palavra latina cor, ou coração, pode, por exemplo, ser contado mais de 8000 vezes em sua obra ${ }^{5}$. Neste artigo, exploraremos a doutrina agostiniana do coração em três movimentos. Primeiro, o convite agostiniano para um encontro com seu coração, sua câmara secreta. Emerge então a pergunta: como Agostinho concebe o coração humano e onde ele se encontra? Segundo, retorne ao seu coração: uma vez que tenhamos localizado o coração, nós paradoxalmente descobrimos que o abandonamos e que precisamos retornar a ele. Terceiro, ascende-se com seu coração: uma vez retornado ao coração, nos levantaremos com ele. Agostinho, como um cardiologista propondo um tratamento, parece nos prescrever um programa médico de cuidado intensivo. Uma importante fonte em que iremos observar os insights de Agostinho sobre o coração humano é em sua famosa obra Confissões ${ }^{6}$. Como epílogo de nossa exposição, vamos explorar de forma concisa dois

\footnotetext{
${ }^{2}$ S. Agostinho, Confissões. Conf. 9, 3. «sagittaueras tu cor nostrum caritate tua».

${ }^{3}$ S. Agostinho, Confissões. Conf. 10, 8. «percussisti cor meum uerbo tuo, et amaui te».

${ }^{4}$ S. Agostinho, Confissões. Conf. 8, 29.

${ }^{5}$ A. Dupont e P. Walraet, «Augustine on the Heart as the Centre of Human Happiness», «Augustine on the Heart as the Centre of Human Happiness», Studies in Spirituality Vol. 25 (2015): 46.

${ }^{6}$ Este artigo é uma síntese original a partir de A. Dupont e P. Walraet, «Augustine on the Heart as the Centre of Human Happiness»: 45-77. Fontes relevantes para o presente artigo foram: I. Bochet, «Coeur», em Saint Augustin. La Méditerranée et l'Europe. IVe-XXIe siècle, ed. A.D. Fitzgerald/M.-A. Vannier (Cerf: Paris 2005), 272-283. K. Demura, «Sursum cor in the Sermons of Augustin», en Prayer and Spirituality in the Early Church, vol. 3: Liturgy and Life, eds. B. Neil, G.D. Dunn, L. Cross (Strathfield: St. Pauls, 2003), 75-81. G. Madec, «Cor», Augustinus-Lexikon 2 (1996-2002): 1-6. A. Maxsein, Philosophia cordis. Das Wesen der Personalität bei Augustinus (Salzburg: Müller, 1966). J. Lescrauwaet, Joseph «"Redite ad cor" - "Keer terug tot uw hart”.
} 


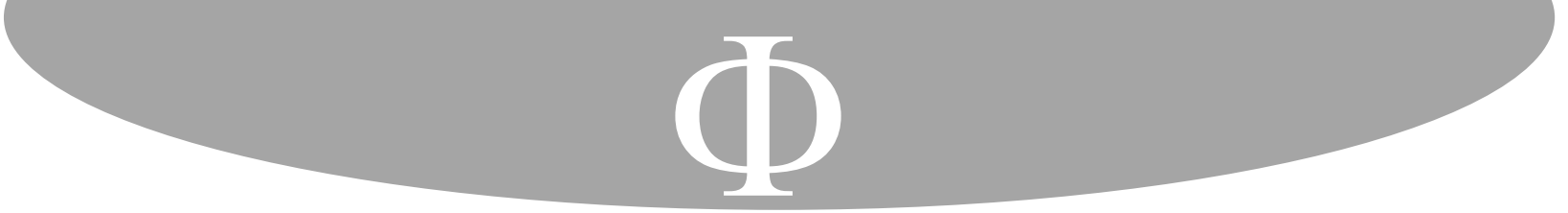

uma dimensão espiritual. O coração, para Agostinho, denota o centro da personalidade e a identidade de todo ser humano. A identidade representa aqui a entidade específica de cada pessoa, uma totalidade de características que me tornam eu mesmo. Em Confissões, Agostinho descreve-o da seguinte forma: «meu coração ... onde eu sou o que (de fato) eu Sou» ${ }^{11}$. Os seres humanos são quem são precisamente a partir do seu coração. O coração é o lugar da interioridade e do eu interior ${ }^{12}$. O coração é uma câmara secreta ${ }^{13}$, a morada interna, muito mais profunda que a área externa ${ }^{14}$.

Durante seus estudos, Agostinho se familiarizou com a psicologia clássica, que era atenta ao simbolismo do coração. A antiguidade clássica considerava o coração como o centro vivificante da pessoa humana. É a fonte do calor, da vida e da consciência. O coração é o símbolo do eu interior, em particular dos desejos e pensamentos mais secretos desta vida interior. Através da leitura dos escritos de filósofos neoplatônicos, Agostinho chegou a novas formulações. Ele escreve:

- Instigado por esses escritos a retornar a mim mesmo, entrei no íntimo do meu coração sob tua guia, e o consegui, porque tu te fizeste meu auxílio. Entrei e, com os olhos da alma, acima destes meus olhos e acima de minha própria inteligência, vi uma luz imutável. Não era essa luz vulgar e evidente a todos com os olhos da carne, ou uma luz mais forte do mesmo gênero. Era como se brilhasse muito mais clara e tudo abrangesse com sua grandeza ${ }^{15}$.

O coração é, portanto, o centro íntimo do ser humano, o lugar onde as capacidades humanas estão concentradas ${ }^{16}$. Isso é ilustrado pelo fato de que, para Agostinho, o coração tinha boca, olhos, orelhas e mãos. O coração, portanto, possui sentidos. Esses sentidos do coração estão relacionados com a experiência de Deus. Em Confissões, Agostinho fala dos sentidos espirituais do coração:

Tu me chamaste, e teu grito rompeu a minha surdez. Fulguraste e brilhaste e tua luz afugentou a minha cegueira. Espargiste tua fragrância e, respirando-a, suspirei por ti. Eu te saboreei, e agora tenho fome e sede de ti. Tu me tocaste, e agora estou ardendo no desejo de tua paz ${ }^{17}$.

\footnotetext{
${ }^{11}$ S. Agostinho, Confissões. Conf. 10,4: «cor meum, ubi ego sum quicumque sum».

12 S. Agostinho, Confissões. Conf. 4,18.

${ }^{13}$ S. Agostinho, Comentário aos salmos (Sao Paulo: Paulus, 1998), 141,3; 41,13.

${ }^{14}$ S. Agostinho, Confissões. Conf. 10,15.

${ }^{15} \mathrm{~S}$. Agostinho, Confissões. Conf. 7,16. «Et inde admonitus redire ad memet ipsum intravi in intima mea duce te et potui, quoniam factus es adiutor meus (Ps. 29:11). Intravi et vidi qualicumque oculo animae meae supra eumdem oculum animae meae, supra mentem meam lucem incommutabilem, non hanc vulgarem et conspicuam omni carni nec quasi ex eodem genere grandior erat, tamquam si ista multo multoque clarius claresceret totumque occuparet magnitudine»

${ }^{16}$ Epist. 147,17,41-20,48.

17 S. Agostinho, Confissões. Conf. 10,38. «Vocasti et clamasti et rupisti surditatem meam, coruscasti, splenduisti et fugasti caecitatem meam; fragrasti, et duxi spiritum et anhelo tibi, gustavi, et esurio et sitio, tetigisti me, et exarsi in pacem tuam».
} 


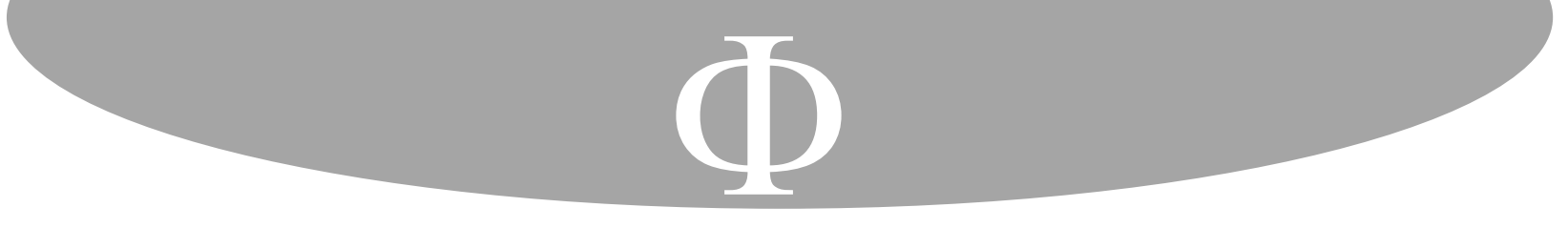

conhecer-me, permita-me conhecer-te». Agostinho, em sua reflexão filosófica em Cassicíaco sobre sua decisão de se converter ao cristianismo, vai em busca de um ponto de referência em sua dúvida quanto ao objetivo e propósito de sua vida, em que sua própria razão o leva ao autoconhecimento e ao conhecimento de Deus como ponto de partida e alvo. O conhecimento de Deus está, em outras palavras, intrinsecamente ligado ao autoconhecimento. O conhecimento de Deus e o autoconhecimento implicam-se mutuamente. Os dois formam um círculo ininterrupto: se alguém quer vir a conhecer a Deus, deve alcançar um entendimento de si mesmo. Deus é encontrado de uma maneira verdadeira dentro de si mesmo. E se alguém quiser entender a si mesmo, tem que se colocar diante de Deus. Quem, ao contrário, não se encontrar, não encontrará Deus ${ }^{24}$. Tal pessoa se desconectou de si mesmo e, portanto, também abafou sua experiência de Deus.

Essa presença divina no núcleo mais profundo da vida humana é descrita por Agostinho por meio de várias imagens bíblicas. O coração é o campo que Deus visita e torna fecundo ${ }^{25}$. É o barco em que Jesus dorme ${ }^{26}$. É o templo de Deus ${ }^{27}$. O coração humano é a casa e a tenda de Deus - tabernacula $D e i^{28}$. Se elevarmos nosso coração a Deus, então, para Deus, esse coração é um altar ${ }^{29}$ e um incensário ${ }^{30}$. No íntimo das profundezas de uma pessoa, no coração, Cristo também vive. Agostinho descreve em um de seus sermões sobre o Evangelho de João: «Retorne ao coração; veja aí talvez o que você pode sentir sobre Deus, porque é onde está a imagem de Deus. Cristo está morando no eu interior; no eu interior você está sendo renovado pela imagem de Deus; em sua imagem, conheça seu autor» ${ }^{31}$. Na ascensão, Cristo desapareceu diante dos nossos olhos - escreve Agostinho - para que pudéssemos retornar ao nosso coração e encontrá-lo lá ${ }^{32}$. Em nosso coração, descobrimos a verdade sobre quem somos. Nós somos a imagem de Deus. A consciência de ser uma imagem e um ser criado nos torna conscientes da existência da origem dessa imagem, de um Criador.

Em suma, o coração é o centro íntimo da personalidade humana, o princípio que une e ordena toda a existência humana, o ponto de encontro entre Deus e a humanidade. Essa percepção foi fundamental para os Soliloquios de Agostinho no tempo de sua conversão: o conhecimento de Deus e o conhecimento de si são idênticos, porque ambos dizem respeito ao conhecimento do próprio coração. $\mathrm{O}$ coração humano, o centro de toda pessoa onde o humano e o divino se encontram, é, desse modo, a interseção e a dobradiça desse conhecimento duplo.

\footnotetext{
${ }^{24}$ S. Agostinho, Confissões. Conf. 5,2.

${ }^{25}$ S. Agostinho, Comentário aos salmos, 58,2,1.

${ }^{26}$ S. Agostinho, Comentário aos salmos, 34,1,3; 45,5; 63,1.

${ }^{27}$ S. 23,7.

${ }^{28} \mathrm{~S}$. Agostinho, Comentário aos salmos, 44,23.

${ }^{29}$ S. Agostinho. A cidade de Deus: contra os pagãos, 10,3; S. Agostinho, Comentário aos salmos, 137,2.

${ }^{30} \mathrm{~S}$. Agostinho, Confissões. Conf. 10,5 : «de fraternis cordibus, turibulis tuis». (Apoc. 8:3-4).

${ }^{31}$ Io. Eu. Tr. 18,10: «redi ad cor; uide ibi quid sentias forte de Deo, quia ibi est imago Dei. In interiore homine habitat Christus, in interiore homine renouaris ad imaginem Dei».

${ }^{32}$ S. Agostinho, Confissões. Conf. 4,19.
} 


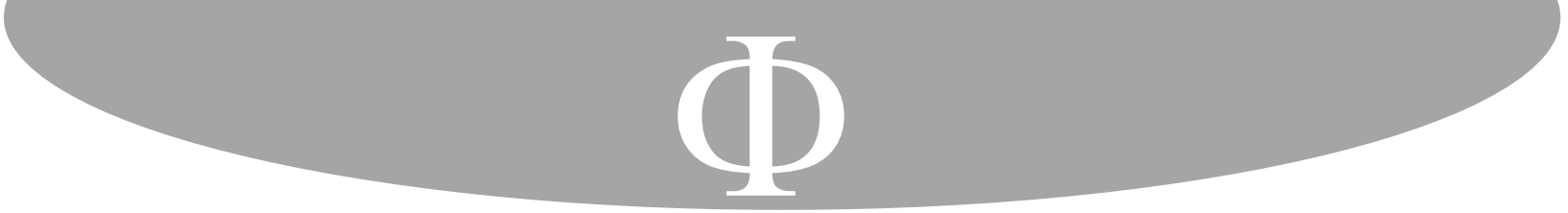

O coração humano, frequentemente, se encontra no lugar errado. Agostinho observa que algumas pessoas têm seu coração deslocado para seus olhos. Outros não têm ouvidos no coração, mas têm o coração nos ouvidos. Elas se empenham em busca do que é sensual, do que é material, ao invés do espiritual e consideram o terreno como um objetivo em si e não como um caminho que leva ao transcendente/celestial. Saem de si mesmos para o que é externo e se esquecem de si. Abandonam-se às coisas externas e dessa maneira se perdem. Sem um retorno ao coração, eles afastam-se de si e, como consequência, o coração inquieto não repousa. Tornou-se desvinculado de si mesmo, fugindo de si mesmo. Agostinho expressa seu próprio desarraigamento com muita força: «trazia a alma despedaçada, a escorrer sangue, qual fardo importuno do qual não sabia descartar-me... Para onde o coração me fugiria de si mesmo? Para onde fugiria de mim mesmo? Para onde eu não me seguiria?» ${ }^{35}$.

Em resumo, Agostinho afirma que seu coração estava vazio da verdade. Por que o coração está distante de si mesmo? Deus é o alicerce do coração humano e aquele que não está mais focado em Deus, está consequentemente distante de si mesmo, de sua própria identidade. Quem não conhece mais a Deus, não conhece mais a si mesmo. Agostinho descreve assim o ato paradoxal de alguém abandonar o seu próprio coração: «meu coração me abandonou» significa que meu coração não está mais em posição de conhecer e compreender a si mesmo. É por isso que Agostinho dá o encorajamento: não se ausentem de Deus, não se ausentem de si mesmos. Onde o autoexame da vida interior é alijado, a pessoa é desvinculada e alienada de Deus e de si mesmo. Agostinho descreve esta alienação em Confissões:

- Ó minha esperança desde a minha juventude, onde estavas, para onde te retiraste? Não foste tu que me criaste e me quiseste diferente dos animais, mais inteligente que as aves do céu? $\mathrm{E}$, no entanto, eu caminhava em meio às trevas e por terrenos escorregadios. Eu te buscava fora de mim, e não encontrava o Deus do meu coração. Havia chegado ao fundo do mar, e não tinha mais confiança nem esperança de encontrar a verdade ${ }^{36}$.

Visto que os sintomas e a natureza da nossa doença cardíaca estão claros, segue-se um caminho terapêutico como um convite ao retorno ao seu coração (Is. 46:8) ${ }^{37}$. Seguindo o exemplo do profeta Isaías, Agostinho insiste que o ser humano precisa retornar ao seu cor. O profeta Isaías reage contra aqueles que se afastaram do verdadeiro Deus e que agora adoram falsos deuses, adoram a ídolos. Dentre os escritos de Agostinho, diversas passagens referem-se a este verso de Isaías, «pecadores, retornem ao seu coração». Assim, ecoando o profeta Isaías, Agostinho deixa claro que o pecador vive fora de seu coração. No quinto livro

\footnotetext{
${ }^{35}$ S. Agostinho, Confissões. Conf. 4,12. «Portabam enim concisam et cruentam animam meam impatientem portari a me... quo enim cor meum fugeret a corde meo? quo a me ipso fugerem? quo non me sequerer?»

${ }^{36}$ S. Agostinho, Confissões. Conf. 6,1. «Spes mea a iuventute mea (Ps. 70:5), ubi mihi eras et quo recesseras (Ps. 10:1)? An vero non tu feceras me et discreveras me a quadrupedibus et a volatilibus caeli sapientiorem me feceras (Job 35:10-11)? Et ambulabam per tenebras et lubricum (Ps. 34:6) et quaerebam te foris a me et non inveniebam Deum cordis mei (Ps. 72:26); et veneram in profundum maris (Ps. 67:23) et diffidebam et desperabam de inventione veri».

${ }^{37}$ Is. 46:8. S. Agostinho, Comentário aos salmos, 57,1-3; 76,5; Io. Ev. Tr. 18,10.
} 


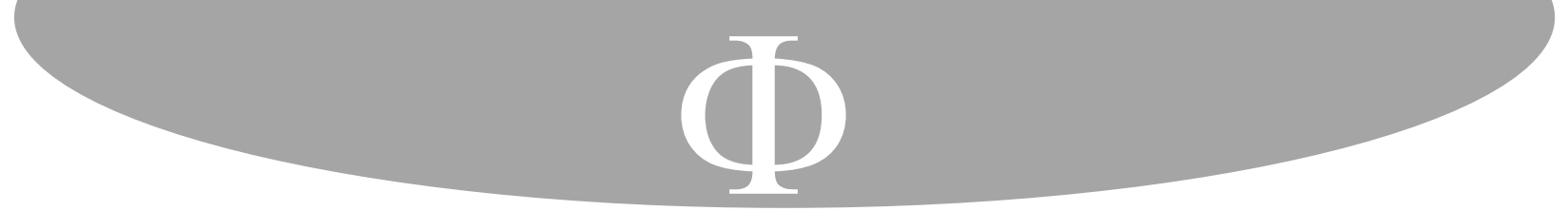

de Confissões, Agostinho escreve a esse respeito: «estavas diante de mim, e eu até de mim mesmo me afastava, e se não encontrava nem a mim mesmo, muito menos podia encontrarte a ti ${ }^{38}$. Agostinho procurava Deus onde Ele não é encontrado. Ao tentar encontrar a felicidade no mundo exterior, em tentações externas e fugitivas, Agostinho, em outras palavras, colocou a criação no lugar de seu Criador, fez um falso ídolo do mundo criado.

Como alguém pode então voltar para Deus? De acordo com o Sermão 311, o caminho de volta a Deus é encontrado por meio do retorno ao coração,

- Retorne ao seu coração e dali para Deus. Estás voltando para Deus, veja você, do lugar mais próximo possível, se retornaste ao seu coração. Porque quando se ofendes com essas coisas de que estamos falando, significa que saiu de si mesmo; se tornou um exilado de seu próprio seio. Estás chateado por coisas fora a você e perde a visão de si mesmo. Tu mesmo estás dentro, esses acréscimos fora. Há coisas boas do lado de fora, mas fora é onde elas estão. Ouro, prata, dinheiro em todas as suas formas, roupas, dependentes, servos, rebanhos, honras, todos eles estão fora. (...) Peça-me coisas melhores, peça-me coisas excelentes; peça-me coisas espirituais; pergunte-me por mim mesmo! $!^{39}$.

Não por fora, mas a partir do interior é preciso se refazer. As semelhanças com a parábola do filho pródigo são claras. Em Sermo 96, sobre o filho pródigo, Agostinho apresenta uma interpretação das palavras do evangelho «quando o filho pródigo voltou para si mesmo...» (Lucas 15:17)

- Ao retornar para si mesmo, o que ele - o filho pródigo - disse para não permanecer em si mesmo? «Vou levantar e ir para o meu pai» (Lc. 15.17-18). Esse é o lugar do qual ele havia caído de si mesmo; ele havia caído de seu pai, ele havia caído de si mesmo. Ele havia se afastado de si mesmo para as coisas do lado de fora. Ele volta para si e parte para o pai, onde ele pode se manter na segurança definitiva ${ }^{40}$.

Primeiro, o reconhecimento do erro dos caminhos, depois o retorno. Agostinho tem ele próprio - como o filho pródigo - tomado o caminho de volta ao seu próprio eu interior, e encontrou, no seu coração, o Pai celestial e seu Filho.

\footnotetext{
${ }^{38}$ S. Agostinho, Confissões. Conf. 5,2. «Et tu eras ante me, ego autem et a me discesseram nec me inveniebam: quanto minus te».

${ }^{39}$ S. 311,13. «Redi ad cor, et inde ad Deum. De proximo enim redis ad Deum, si redieris ad cor tuum. Nam quando te ista offendunt, existi et a te: exsul factus es pectoris tui. Moveris rebus quae sunt foris a te, et perdis te. Tu intus es, ista foris adiacent; foris bona sunt, sed foris sunt. Aurum, argentum, omnis pecunia, vestis, clientela, familiae, pecora, honores, foris sunt. ... Quia ergo vides quibus ea dederim; meliora pete a me, maiora pete a me; spiritalia pete a me, ipsum me pete a me».

${ }^{40}$ S. 96,2. «Si reversus est ad se, exierat a se. Quia ceciderat a se, et exierat a se, redit prius ad se, ut redeat in illo unde ceciderat a se. Sicut enim cadendo a se, remansit in se: sic redeundo ad se, non debet remanere in se, ne iterum exeat a se. Reversus ad semetipsum, ut non remaneret in semetipso, quid dixit? Surgam, et ibo ad patrem meum (Lk. 15:17-18). Ecce unde ceciderat a se, ceciderat a patre suo: ceciderat a se, ad ea quae foris sunt exiit a se. Redit ad se, et pergit ad patrem, ubi tutissime servet se».
} 


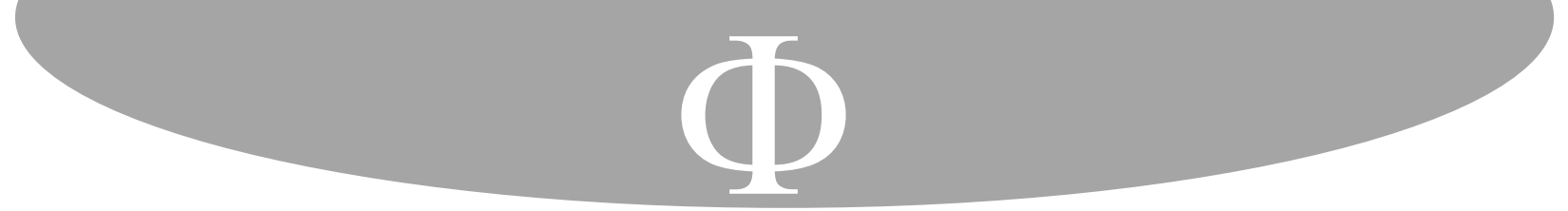

- e tu, Senhor, enquanto ele falava, me fazias refletir sobre mim mesmo, tirando-me da posição de costas, em que eu me havia colocado para não me enxergar a mim mesmo, e me colocavas diante de minha própria face, para que eu visse quanto era indigno, disforme e sórdido, coberto de manchas e de chagas. E eu via, e me horrorizava, e não tinha como fugir de mim mesmo ${ }^{51}$.

Retornar ao próprio coração envolve tornar-se consciente da própria insignificância e miséria e, com base nessa consciência, confiar-se a si mesmo à compaixão divina. Aqui descobrimos o duplo significado de confessio / confessiones - o título latino de Confissões, admissão do pecado e louvor de Deus. Confessio significa primeiro reconhecer a própria pecaminosidade, isto é, reconhecer a incapacidade fundamental do homem decaído de se restaurar. Na mais profunda consciência de seus próprios fracassos, o homem descobre o Deus misericordioso e compassivo, que o cura e restaura - a razão para louvar a Deus, o segundo significado da confessio. Retornando ao coração ele está redescobrindo Deus no centro do próprio ser e permitindo-se ser recriado por ele.

\section{Terceiro Movimento: ASCENDE com o coração}

Uma terapia intensiva cura novamente o coração, e um coração saudável, de acordo com Agostinho, é um coração ascendente, com o amor como seu marca-passo.

\subsection{Subindo como fogo}

Para Agostinho, a redite ad cor vai de mãos dadas com o sursum cor: o retorno ao coração é acompanhado pela subida da alma a Deus. Elevar-se com o coração significa que se chega mais perto de Deus, se aproxima de Deus ${ }^{52}$. Somos chamados a este movimento no diálogo introdutório da oração eucarística Sursum cor - habemus ad Dominum: «Corações ao alto - o nosso coração está em Deus». O coração descobre em sua intimidade mais profunda em uma dinâmica que leva ao coração continuamente mais alto, «uma subida do visível para o invisível, do temporal para o eterno» ${ }^{53}$. De forma concisa, Agostinho nos exorta: «Deixe o terreno para o terreno, levante o coração no alto» ${ }^{54}$. O ambiente natural do movimento do coração é, como o fogo, para as alturas ${ }^{55}$. O bispo Agostinho exorta seus ouvintes: «Levante seus irmãos e irmãs de coração, levante-os o mais alto que puder» ${ }^{56}$. E no Comentário de Agostinho sobre o Salmo 132 (133), lemos um texto poderoso a respeito sursum cor: «estás angustiado na terra? Emigra, mora no céu. Como, dirás, habitarei no céu, ainda revestido de carne, sujeito à carne? Precede com o coração; para lá seguirás com o

\footnotetext{
${ }^{51}$ S. Agostinho, Confissões. Conf. 8,16. «Tu autem, Domine, inter verba eius retorquebas me ad me ipsum, auferens me a dorso meo, ubi me posueram, dum nollem me attendere (Ps. 20:13), et constituebas me ante faciem meam (Ps. 49:21), ut viderem, quam turpis essem, quam distortus et sordidus, maculosus et ulcerosus. Et videbam et horrebam, et quo a me fugerem non erat (Ps. 138:7)».

${ }^{52} \mathrm{~S}$. Agostinho, Comentário aos salmos, 122,3.

${ }^{53}$ Ver. Rel. 29,52.

${ }^{54}$ Io. Ev. Tr. $18,6$.

${ }^{55}$ S. Agostinho, Confissões. Conf. 13,10.

56 S. 120,2 .
} 


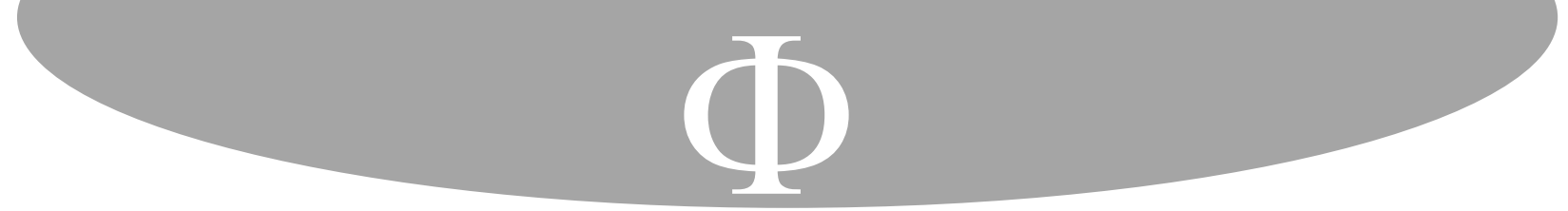

como isso. Você deve amar seu próximo como a si mesmo [Lev. 19: 8]. Nestes dois mandamentos, toda a lei e os profetas dependem ${ }^{64}$.

Este duplo mandamento do amor é um fio condutor que Agostinho retorna continuamente em seu pensamento. Amor a Deus e amor ao próximo. O duplo mandamento para o amor gira em torno desses dois amores, que juntos formam uma unidade. Para Agostinho, o amor a Deus é a forma mais elevada de amor; e o amor ao próximo, é secundário a ele. O vizinho não pode tomar o lugar de Deus. A posição aparentemente subordinada do amor pelo próximo deve ser qualificada de duas maneiras. Primeiro, Agostinho distingue duas ordens de amor: a ordem do que é exigido e a ordem de ação. A subordinação do amor ao próximo ao amor por Deus só pode ser encontrada no nível do que é prescrito, no nível teórico. Em relação ao que é prescrito, Deus vem em primeiro lugar, o próximo em segundo. No nível da vida cotidiana, em relação às atividades humanas, o amor pelo próximo vem em primeiro lugar. Na prática, o próximo vem primeiro, depois Deus. Durante esta vida terrena, só se pode amar a Deus através de seu semelhante. Segundo, como já foi indicado, Deus já é amado no próximo, que carrega a imagem de Deus. $\mathrm{O}$ amor por Deus é, portanto, amor pelo próximo. O amor pelo próximo é amor a Deus. Ambos os amores são iguais e exigem um ao outro. São dois lados da mesma moeda: podem ser distinguidos, mas não separados. Eles não podem existir sem o outro. Juntos eles carregam as partes complementares da mesma moeda.

A teologia do amor de Agostinho também ensina a forma adequada de amor-próprio. Com uma alusão à história bíblica do Filho Pródigo, Agostinho referenda que sua posição de entregar-se a Deus não significa perder-se, mas sim (re) descobrir-se. A preferência do filho pródigo por determinar sua própria companhia o afastou de seu pai. Ele se distanciou de seu pai e também de si mesmo. O Filho Pródigo precisava primeiramente retornar a si mesmo. Depois de reconhecer os erros de seus caminhos, ele decidiu não permanecer sozinho, mas retornar para o pai e a si mesmo. Amar a Deus é reencontrar-se consigo mesmo: ame a Deus com tudo o que você tem, só assim você pode amar a si mesmo, e portanto amar seu próximo como a si mesmo ${ }^{65}$.

A inquietação do coração humano cria uma certa dinâmica que direciona os humanos para uma determinada meta. O objetivo do coração humano é o amor. Para Agostinho, esse amor é um nome para Deus - «Deus dilectio / caritas est», de acordo com o apóstolo João ${ }^{66}$. No entanto, o amor não é apenas o objetivo mais elevado, mas é ao mesmo tempo a dinâmica que conduz e leva os seres humanos a esse amor,

\footnotetext{
${ }^{64}$ Mt. 22:37-40. Lc. 10:27.

65 Buscando evitar um falso amor ao próximo, Agostinho acrescenta no sermão 90A que um praeceptum (mandamento) seria realmente suficiente: «amarás teu ao próximo como a ti mesmo». Somente o amor próprio baseado em Deus leva a um adequado amor pelo próximo. Agostinho prega à sua congregação que Deus confiou a cada um o seu próximo para que você possa amá-lo como a si mesmo. Se entendemos porque o Senhor deu dois praecepta, um praeceptum é na verdade o suficiente. O primeiro e o segundo praeceptum estão conectados de maneira inseparável. O segundo está originado no primeiro. A escolha pelo amor ao próximo não será genuína, a menos que Deus também seja amado. A escolha pelo amor a Deus não será autêntica, a menos que o próximo seja incluído.

661 John $4: 16$
} 


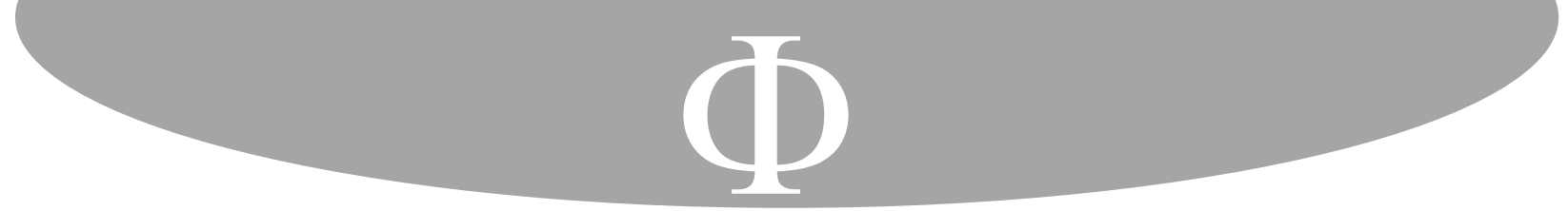

Em teu dom repousamos e nele gozamos em ti. Ele é o nosso descanso, é o nosso lugar. É para lá que o amor nos arrebata. O Espírito Santo nos eleva a humildade, afastando-a das portas da morte. Na tua boa vontade temos a paz. Todo corpo, devido ao peso, tende para o lugar que lhe é próprio, porque o peso não tende só para baixo, mas também para o lugar que lhe é próprio. Assim, o fogo tende para o alto, a pedra para baixo. Por seu peso são impelidos para o seu justo lugar. O óleo derramado sobre a água aflora à superfície; a água, jogada sobre o óleo, submerge. São ambos impelidos por seu peso a procurar o próprio posto. Onde há desordem reina a agitação, e na ordem reina a paz. Meu peso é o amor; por ele sou levado para onde sou levado. Teu dom nos inflama e nos leva para o alto; nós nos inflamamos e nos movemos. Subimos os degraus do coração, cantando o cântico dos degraus. É o teu fogo, o teu fogo santo que nos inflama e nos move, enquanto subimos para a paz de Jerusalém ${ }^{67}$.

A conversão do coração ocorre em amor a Deus e amor pelo próximo. $\mathrm{O}$ amor purifica os olhos do coração para que alguém possa ver a Deus. Agostinho ensina que quem não vê a Deus é alguém que não ama a Deus. E se não houver amor por Deus, não haverá amor pelo próximo. Em seus sermões sobre a primeira epístola de João, Agostinho diz: «Assim, quem tem o amor, vê a Deus, porque "Deus é amor". E aquele olho interior se purifica mais e mais, pelo amor. Tornar-se-á capaz de contemplar essa substância imutável cuja presença sempre o alegrará, pois dela gozará na eternidade» ${ }^{68}$.

Retornar ao seu coração significa, portanto, voltar ao que é o núcleo de uma autêntica existência humana. Retornar ao seu coração é, em outras palavras, o chamado para não se fechar em si mesmo. Voltar ao centro de nós mesmos é descobrir que há algo ou alguém que é muito maior que nós mesmos. Retornar ao nosso verdadeiro eu é se reabrir para aquele que em todos os sentidos nos ultrapassa. Voltar para nós mesmos é redescobrir a verdade sobre o nosso próprio ser, e essa verdade é amor, o amor que é Deus. Experimentamos em nossas próprias vidas que o amor ultrapassa nosso entendimento humano, assim como Deus o faz. Esta verdade sobre o amor - nosso coração é verdadeiramente determinado pelo amor - é ao

\footnotetext{
${ }^{67}$ S. Agostinho, Confissões. Conf. 13,10. «In dono tuo requiescimus: ibi te fruimur. Requies nostra locus noster. Amor illuc attollit nos et spiritus tuus bonus (Ps. 142:1) exaltat humilitatem nostram de portis mortis (Ps. 9:15) In bona voluntate pax nobis est (Lk. 2:14). Corpus pondere suo nititur ad locum suum. Pondus non ad ima tantum est, sed ad locum suum. Ignis sursum tendit, deorsum lapis. Ponderibus suis aguntur, loca sua petunt. Oleum infra aquam fusum super aquam attollitur, aqua supra oleum fusa, infra oleum demergitur; ponderibus suis aguntur, loca sua petunt. Minus ordinata inquieta sunt: ordinantur et quiescunt. Pondus meum amor meus; eo feror, quocumque feror. Dono tuo accendimur et sursum ferimur; inardescimus et imus. Ascendimus ascensiones in corde (Ps. $83: 6$ ) et cantamus canticum graduum (Ps. 119:1). Igne tuo, igne tuo bono inardescimus et imus, quoniam sursum imus ad pacem Hierusalem, quoniam iucundatus sum in his, qui dixerunt mihi: In domum Domini ibimus (Ps. 121:6). Ibi nos collocabit voluntas bona, ut nihil velimus aliud quam permanere illic in aeternum (Ps. 60:8)».

68 John 4:16. Io. Ep. tr. 9,10. «Nam si habeat dilectionem, Deum videt; quia Deus dilectio est: et purgatur ille oculus magis magisque dilectione, ut videat illam incommutabilem substantiam; cuius praesentia semper gaudeat, qua perfruatur in aeternum coniunctus Angelis». S. Agostinho, Comentário da primeira epístola de São João, Trad. Nair de Assis Oliveira (São Paulo: Paulinas, 1989).
} 


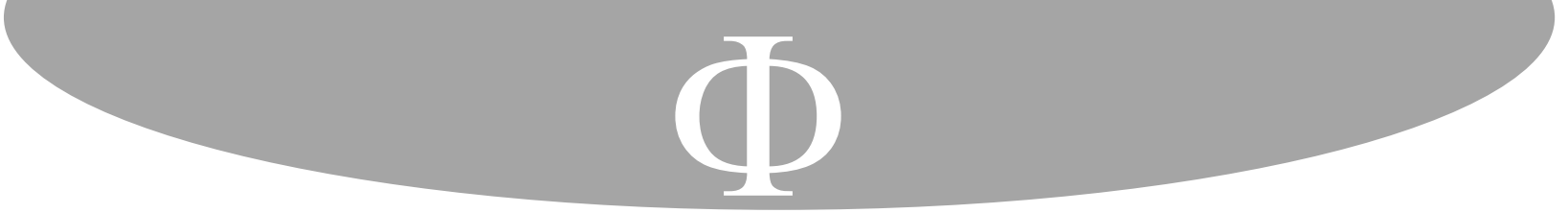

\section{Conclusão}

Embora este artigo não recomende Confissões de Agostinho como um manual para cardiologistas, espera-se ter demonstrado como o coração inflamado e perfurado de Agostinho oferece uma análise fascinante da pessoa humana. De acordo com o bispo de Hipona, o símbolo do coração denota nossa mais profunda intimidade e identidade. Agostinho aqui prenuncia um dos principais pontos de interesse do dogma filosófico do personalismo do século XX, a subjetividade humana ou autoconsciência, experimentada nos próprios atos e acontecimentos internos de uma pessoa.

Muitas vezes, porém, perde-se a noção do centro interior e, consequentemente, o coração fica inquieto, à deriva, infeliz. Essa alienação do coração exige uma reconfiguração, uma reorientação, denominada teologicamente como «conversão». Voltando ao verdadeiro eu, abre-se para um Amor que em todos os sentidos nos ultrapassa. Em suas Confissões, Agostinho expressou poeticamente: Deus é interior intimo meo, e superior summo meo, mais interno do que parte mais interior e superior ao elemento mais alto dentro de mim.

De fato, os seres humanos permanecem com demasiada frequência na superfície da existência, abandonam o coração e se esquecem daquele que vive no coração. A busca contínua de distrações ou a imersão no trabalho podem ser mecanismos que evitam a reflexão sobre o significado da vida, atitude corriqueira na sociedade contemporânea. Pode-se não tolerar um silêncio autêntico, descansar verdadeiramente, porque então alguém é confrontado com si mesmo. Porém, é possível que, assim como Agostinho, nossa humanidade tome consciência do vazio da existência. Ao perceber que a vida é preenchida de maneira sem sentido para não sentir seu vazio, é o momento de ouvir o convite de Agostinho: retorne para seu coração. Levante-se com o seu coração! Conheça a si mesmo, conheça a Deus! Ame a Deus, ame seu próximo e ame-se! Ore e aja de acordo com o seu coração! Seja uno de coração.

\section{Bibliografia}

Agostinho, Santo. A cidade de Deus: contra os pagãos. 4.ed. Trad. Oscar Paes Leme. Petrópolis: Vozes, 2001.

Agostinho, Santo. A regra de Santo Agostinho. Petrópolis: Vozes, 2009.

Agostinho, Santo. Comentário ao Evangelho e ao Apocalipse de São João. Trad. José Augusto Rodrigues Amado. São Paulo: Cultor de Livros, 2017.

Agostinho, Santo. Comentário aos salmos. Sao Paulo: Paulus, 1998.

Agostinho, Santo. Comentário da primeira epístola de São João. Trad. Nair de Assis Oliveira. São Paulo: Paulinas, 1989.

Agostinho, Santo. Confissões. Trad. Maria Luíza Jardim Amarante. São Paulo: Paulus, 1984. Agostinho, Santo. Sobre o sermão do Senhor na montanha. Trad. Carlos Ancêde Nougué. Campo Grande: Edições Santo Tomás, 2013. 
